\title{
PENGARUH PENGGUNAAN MEDIA AUDIO VISUAL TERHADAP MINAT BELAJAR BIOLOGI SISWA PADA MATERI PLANTAE DI KELAS X SMA SWASTA AMAL BAKTI MEDAN TAHUN PEMBELAJARAN 2016/2017
}

\author{
Radita Aulia Swastika ${ }^{{ }^{*}}$, Ahmad Shafwan Pulungan ${ }^{1}$, Ratna Kekal Bariani ${ }^{2}$ \\ ${ }^{1}$ Program Studi Pendidikan Biologi, FMIPA, Universitas Negeri Medan, Medan Jl. Willem Iskandar Psr. V Medan \\ Estate, Medan, Indonesia, 20221 \\ ${ }^{2}$ SMA Swasta Amal Bakti Medan, Jalan Kayu Putih No. 23 Mabar, Medan, Indonesia, 20241 \\ *E-mail : raditaauliaswastika@gmail.com
}

\begin{abstract}
ABSTRAK
Penelitian ini bertujuan untuk mengetahui pengaruh penggunaan media audio-visual terhadap minat belajar biologi siswa pada materi plantae di kelas X SMA Swasta Amal Bakti Medan tahun pembelajaran 2016/2017. Jenis penelitian ini adalah penelitian deskriftif. Subjek penelitian ini adalah siswa kelas X SMA Amal Bakti. Sampel yang digunakan adalah 38 orang siswa kelas $X$. Instrumen penelitian yang digunakan adalah angket sebanyak 30 pertanyaan dengan jawaban tertutup. Penggunaan media audio visual dalam proses pembelajaran berpengaruh terhadap minat belajar siswa pada mata pelajaran biologi pada materi Plantae. Hasil penelitian ini menunjukkan bahwa secara keseluruhan siswa mengalami peningkatan minat belajar sebesar $4,12 \%$ setelah proses pembelajaran di bantu dengan media audio visual berupa video pembelajaran. Dan indikator dalam minat belajar mengalami peningkatan, yaitu rasa senang $(13,1 \%)$, rasa ingin tahu $(4,7 \%)$, rasa tertarik $(5,7 \%)$, rasa nyaman $(1 \%)$ dan antusiasme siswa $(3,9 \%)$ terhadap guru biologi dan pelajaran biologi.
\end{abstract}

Kata kunci : media audio visual, minat belajar, plantae

\section{ABSTRACT}

This study aims to determine the effect of the use of audio visual media on the interest of learning biology of students on plantae material in the class X Private High School Amal Bakti Medan in the 2016/2017 academic year. The type of this research is descriptive research. The subject of this research is the students of grade $X$ of Private High School Amal Bakti. Samples used 38 students of class X. The research instrument used is a test about questionnaire as many as 30 questions with closed answer. The use of audio visual media in the learning process affect the interest of learning student on the subject of biology on Plantae material. The results of this study indicate that overall students experience increased interest in learning of $4.12 \%$ after the learning process in aids with audio-visual media in the form of learning videos. And the indicators used to measure interest in learning, namely pleasure $(13.1 \%)$, curiosity $(4.7 \%)$, interest $(5.7 \%)$, comfort $(1 \%)$ and student enthusiasm $(3,9 \%)$ towards biology teachers and biology lessons.

Keyword: audio visual media, interest learning, Plantae

\section{PENDAHULUAN}

Pendidikan berperan penting dalam menjamin kelangsungan hidup bangsa dan negara, terutama bagi suatu negara yang sedang berkembang seperti negara Indonesia. Pendidikan merupakan salah satu faktor yang membentuk watak, kepribadian, tingkah laku, serta pola pikir seorang manusia. Sekolah merupakan sarana pendidikan formal agar manusia bisa mengembangkan potensi dirinya dengan bantuan seorang pembimbing yang akan membimbing dan mengarahkan. Materi yang disajikan dalam pelajaran biologi cenderung didominasi oleh teori-teori atau konsep sehingga dalam mempelajarinya diperlukan daya ingat yang cukup kuat. Penggunaan sumbersumber belajar seperti media pembelajaran kurang dimanfaatkan secara optimum oleh guru biologi di sekolah SMA Swasta Amal Bakti tersebut. Keadaan ini menyebabkan minat siswa atau ketertarikan siswa di SMA Swasta Amal Bakti khususnya kelas $\mathrm{X}$ terhadap pelajaran biologi menjadi rendah tau tidak ada sama sekali, padahal minat belajar itu sendiri merupakan salah satu aspek psikologi dari seorang manusia yang memperlihatkan sebuah atau beberapa gejala akan suatu hal, misalnya keinginan, perasaan suka atau 
gairah untuk melakukan suatu kegiatan belajar yang melalui sebuah proses perubahan tingkah laku yang berhubungan dengan pengetahuan dan pengalaman pada suatu kegiatan pembelajaran yang dilakukannya ((Hamalik (1994); Arsyad (2015)).

Di sekolah ini proses pembelajarannya belum pernah menggunakan media pembelajaran selain papan tulis dan kendala terbesar dalam proses pembelajaran di sekolah ini adalah tidak semua murid di sekolah memiliki buku pengangan karena ketidak mampuan keuangan dari orang tua murid dan masih minimnya anggaran dari pemerintah melalui program Bantuan Operasional Sekolah yang teralokasikan untuk buku-buku pembelajaran, sehingga buku yang disediakan sekolah tidak sebanding dengan jumlah siswa. Hal ini yang mengakibatkan mereka jarang memperhatikan guru yang sedang menerangkan didepan kelas. Dan hanya memilih untuk mencatat apa yang ditulis di papan tulis. Untuk mempermudah proses pembelajaran yang berlangsung di sekolah SMA Swasta Amal Bakti Medan dengan kendala seperti yang telah dijabarkan sebelumnya, maka melalui media pembelajaran yang tepat, guru dapat menarik perhatian dan minat belajar siswa serta dapat melibatkan siswa semaksimal mungkin dalam kegiatan pembelajaran yang sedang berlangsung. Jadi untuk menarik minat belajar siswa, seorang guru harus mampu memilih media pembelajaran yang tepat dan sesuai dengan materi pelajaran yang akan disampaikan. Salah satu media pembelajaran yang bisa digunakan dalam proses pembelajaran di sekolah SMA Swasta Amal Bakti Medan adalah media audiovisual. Media audio-visual merupakan media yang menyampaikan materi dengan menggunakan suara dan gambar, salah satu contohnya adalah video yang berkaitan dengan materi pelajaran yang akan disampaikan oleh guru.

Minat adalah keinginan seseorang yang didorong oleh suatu rasa ingin dan ketertarikan setelah melihat, mengamati dan membandingkan serta mempertimbangkan dengan kebutuhan yang diinginkannya (Fajariah, 2016). Minat belajar diartikan sebagai kecenderungan untuk mempelajari sesuatu dengan perasaan senang. Hal ini didasari oleh pendapat Slameto, (2010) yang menyatakan bahwa
“Minat belajar adalah rasa lebih suka dan rasa tertarik pada suatu hal atau aktivitas tanpa ada yang menyuruh". Minat Belajar yang dimaksudkan adalah minat belajar yang meliputi perasaan senang, perhatian, kosentrasi dan kemauan siswa terhadap suatu mata pelajaran tertentu. Materi dunia tumbuhan (plantae) merupakan materi pelajaran biologi yang keberadaannya sebenarnya sangat dekat dengan kehidupan kita, namun pada kenyataannya kebanyakan siswa di sekolah SMA Swasta Amal Bakti Medan sulit untuk mengingat nama latin dan nama daerah dari spesies pada kingdom ini serta manfaatnya karena jenisnya yang cukup berangam sehingga siswa cenderung tidak bisa mengingat dengan baik divisi atau nama latin dari tumbuhan yang ada disekitarnya. Media video cocok digunakan untuk membantu proses belajar mengajar pada materi dunia tumbuhan (plantae) di kelas X SMA Swasta Amal Bakti terutama untuk meminimalisir adanya miss konsepsi dan miss komunikasi antara guru dan murid.

Tujuan penelitian ini adalah untuk mengetahui berapa persen pengaruh penggunaan media audio-visual terhadap minat belajar biologi siswa pada materi plantae di kelas X SMA Swasta Amal Bakti Medan Tahun Pembelajaran 2016/2017. Penelitian dilakukan pada siswa kelas X SMA Swasta Amal Bakti Medan. Data hasil penelitian dapat dijadikan sebagai salah satu rujukan dalam penggunaan media pembelajaran yang tepat dalam proses pembelajaran biologi, terkhusus media audio visual.

\section{METODE PENELITIAN}

Penelitian ini dilaksanakan di SMA Swasta Amal bakti Medan Lokasi yang terletak di Jalan Kayu Putih No. 32, Mabar, Medan pada bulan Desember sampai dengan Juni tahun 2017. Jenis penelitian ini adalah deskriptif. Subjek daalam penelitian adalah seluruh siswa kelas X SMA Swasta Amal Bakti Medan Tahun Pembelajaran 2016/2017. Jumlah subjek sebanyak 38 siswa. Data diperoleh melalui angket (sebagai data utama).

Angket yang digunakan adalah angket tertutup yang terdiri dari 30 item pernyataan. Masing-masing 
pernyataan disediakan empat pilihan yang menjadi alternatif jawaban dan perhitungan skor menggunakan skala linkert dengan ketentuan: 1= tidak pernah, 2= kadang-kadang, 3= sering, 4= selalu. Indikator dalam minat belajar yang diteliti meliputi: 1)Rasa senang terhadap guru dan pelajaran biologi; 2) Rasa ingin tahu akan materi dalam pelajaran biologi; 3)Rasa tertarik terhadap pelajaran biologi; 4)Rasa nyaman saat belajar biologi; 5) Antusiame siswa terhadap pelajaran biologi Masing-masing indikator terdiri dari 6 item pernyataan.

Teknik analisis data untuk hasil angket dianalisis secara deskriptif kuantitatif. Untuk hasil angket yang telah diskoring selanjutnya dianalisis secara deskriptif persentase dengan menggunakan rumus berikut.

$$
\text { presentasi jawaban }=\frac{\text { jumlah skor jawaban siswa }}{\text { jumlah skor maksimum }} \times 100 \%
$$

Melakukan interprestasi jawaban angket dengan cara membuat kategori untuk setiap kriteria dengan uraian sebagai berikut;

$$
\begin{array}{ll}
0 \%-20 \% & =\text { Sangat tidak berminat } \\
21 \%-40 \% & =\text { Kurang berminat } \\
41 \%-60 \% & =\text { Cukup berminat } \\
61 \%-80 \% & =\text { Berminat } \\
81 \%-100 \% & =\text { Sangat berminat }
\end{array}
$$

Mencari kategori hasil rata-rata skor angket seluruh siswa dari tiap indikator digunakan rumus:

$$
\text { Skor Indikator }=\frac{\text { jumlah skor yang diperoleh seluruh siswa }}{\text { jumlah skor maksimum tiap indikator }} \times 100 \%
$$

Kategori :

$85 \%-100 \%=$ Minat Siswa Tinggi

$75 \%-84 \%=$ Minat Siswa Sedang

$61 \%-74 \%=$ Minat Siswa Rendah

$0 \%-60 \%=$ Minat Siswa Sangat Rendah

\section{HASIL PENELITIAN}

Berdasarkan hasil analisa angket minat belajar siswa pada lima indikator minat belajar siswa (rasa senang, rasa rasa ingin tahu, rasa tertarik, rasa nyaman dan antusiasme siswa) dalam mempelajari materi Plantae di kelas X SMA Swasta Amal Bakti Medan Tahun Pembelajaran 2016/2017 memiliki rerataan sebesar $54,50 \%$ dan $58,62 \%$ yang tergolong dalam kategori cukup berminat. Dari hasil tersebut dapat diketahui bahwa minat belajar biologi siswa meggalami peningkatan meskipun dalam kategori yang sama. Skor angket minat belajar siswa secara keseluruhan berdasarkan indikator tersebut dideskripsikan sebagai berikut: 1) Rasa senang mengalami peningkatan sebesar 13,1\%; 2) Rasa ingin tahu mengalami peningkatan sebesar 4,7\%; 3) Rasa tertarik mengalami peningkatan sebesar 5,7\%; 4) Rasa nyaman mengalami peningkatan sebesar 1\%; 5) Rasa antusiasme siswa mengalami peningkatan sebesar 3,9\%. Hasil penjabaran diatas dapat dibuat dalam bentuk grafik seperti Gambar 1. 


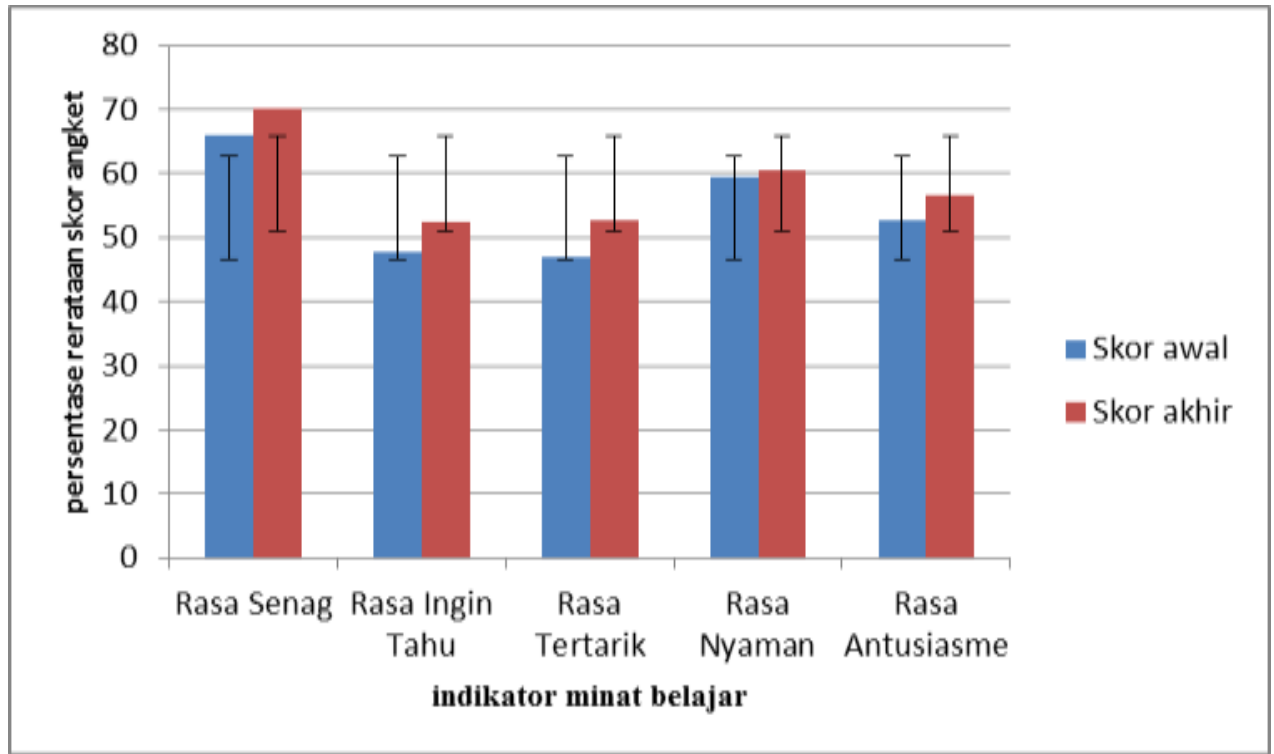

Gambar 1. Grafik Rerataan Indikator dalam Minat Belajar Biologi Siswa Kelas X SMA Swasta Amal Bakti Medan

\section{PEMBAHASAN}

Penggunaan media audio visual berupa video pembelajaran berpengaruh terhadap minat belajar siswa berdasarkan lima indikator minat diatas. Karena pada dasarnya seorang manusia cenderung lebih tertarik pada pesan-pesan simbolik atau gambar yang di seligi oleh suara (audio) dan berdasarkan pendapat Achsin (1986) dan Dale (1969) bahwa seseorang dapat dengan mudah menerima informasi lebih dari $70 \%$ informasi yang diberikan melalui indera pengelihatan dan sisanya melalui indera pendengaran. Sehingga ketika siswa belajar dengan bantuan media audiovisual (video pembelajaran yang menggunakan sistem indera ganda (melihat dan mendengar) menyebabkan munculnya rasa suka dan ketertarikan siswa kelas $X$ SMA Swasta Amal Bakti Medan terhadap pelajaran biologi pada materi plantae karena yang disajikan oleh guru berupa gambar dan simbol serta saat menyajikan video diseligi dengan penjelasan oleh guru sehingga pembelajaran tidak monoton dan siswa tidak cepat jenuh saat proses pembelajaran berlangsung (Purwono, 2014). Hal ini juga berhubungan dengan gaya belajar dari siswa yang bersangkutan. Gaya belajar sendiri terdiri atas tiga, yakni, gaya belajar visual (cenderung lebih suka melihat apa yang ingin dipelajari dan dipahami), auditori (cenderung lebih suka mendengar suara untuk memahami suatu materi pelajaran), dan kinestetik (cenderung lebih suka menyentuh sesuatu atau bergerak saat proses pembelajaran berlangsung agar mudah memahami suatu hal) (Bire, dkk., 2014). Pada penelitian ini dapat terlihat bahwa gaya belajar yang digunakan oleh siswa kelas X SMA Swasta Amal Bakti Medan secara keseluruhan adalah gabungan dari gaya belajar visual dan auditori, sehingga saat proses pembelajaran mengunakan media audio Visual siswa dikelas tersebut lebih mudah fokus dan berkonsentrasi dalam mengikuti kegiatan belajar mengajar.

Maka, dapat disimpulkan bahwa penggunaan media pembelajaran dalam penelitian ini berupa media video pembelajaran berpengaruh terhadap minat belajar biologi siswa pada materi plantae di kelas X SMA Swasta Amal Bakti Medan T.P 2016/2017. Dan penggunaan media pembelajaran dalam kegiatan belajar mengajar sangat penting untuk membangun minat belajar siswa. Menurut Brunner (1966) dalam Arsyad (2015) pada dasarkan manusia memperoleh pengetahuan dan keterampilan serta mengalami perubahan sikap dan perilaku yang disebakan oleh adanya interaksi seorang individu terhadap pengalaman baru dengan pengalaman yang pernah dialami oleh individu tersebut sebelunnya. Ada tiga tingkatan utama modus belajar, yaitu pengalaman 
langsung (enactive), pengalaman piktorial/gambar (iconic) dan pengalaman abstrak (symbolic). Dan untuk siswa kelas X SMA Swasta Amal Bakti Medan Tahun Pembelajaran 2016/2017 yang mempelajari tentang materi Plantae yang dibantu dengan media video pembelajaran mengalami ketiga tingkatan modus belajar tersebut yang tidak lepas dengan gaya belajar mereka yang merupakan gabungan gaya belajar visual dan auditori, yakni saat guru menjelaskan menggunakan media video mengenai materi dunia tumbuhan, siswa akan melihat gambaran dari tumbuhan yang ditampilkan didalam video dan membandingkannya dengan apa yang dilihat oleh siswa di lingkungan sekolah saat proses pembelajaran berlangsung atau mengingat jenis tumbuhan yang pernah siswa tersebut lihat sebelumnya.sehingga informasi mengenai materi plantae lebih mudah dimengerti dan dapat lebih lama diingatan oleh siswa khususnya pada penelitian ini adalah siswa kelas $X$ di sekolah SMA Swasta Amal Bakti Medan.

\section{KESIMPULAN}

Hasil penelitian menunjukkan bahwa pengaruh penggunaan media audio visual terhadap minat belajar siswa pada materi Plantae di kelas X SMA Swasta Amal Bakti Medan Tahun Pembelajaran 2016/2017 mengalami peningkatan sebesar 4,12\%. Dan indikator dalam minat belajar biologi siswa juga mengalami peningkatan yakni rasa senang $(13,1 \%)$, rasa ingin tahu $(4,7 \%)$, rasa tertarik $(5,7 \%)$, rasa nyaman (1\%) dan rasa antusiasme siswa (3,9\%). Hasil ini menunjukkan bahwa penggunaan media video pembelajaran dapat membantu meningkatkan minat belajar biologi siswa pada materi Plantae di Kelas $\mathrm{X}$ SMA Swasta Amal Bakti Medan Tahun Pembelajaran 2016/2017.

\section{UCAPAN TERIMA KASIH}

Terima kasih kepada Bapak Sugeng Permono, SH selaku Kepala Sekolah SMA Swasta Amal Bakti Medanyang telah banyak membantu selama penelitian berlangsung.

\section{DAFTAR PUSTAKA}

Achsin, A., (1986), Media Pendidikan dalam Kegiatan Belajar Mengajar, Institut Keguruan Ilmu Pendidikan Ujung Pandang, Ujung Pandang.

Arsyad, A., (2015), Media Pembelajaran Edisi Revisi, Divisi Buku Perguruan Tinggi, Raja Grafindo Persada, Jakarta.

Bire, A. L., Geradus, U., dan Bire, J., (2014), Pengaruh Gaya Belajar Visual, Auditorial, dan Kinestetik Terhadap Prestasi Belajar Siswa, Jurnal Kependidikan, 44 (2): 168-174.

Bruner, J. S., (1966), Toward a Theory of Instruction, Harvard University, Cambridge.

Dale, E., (1969), Audiovisual Methos in Teaching (Third Edition), The Dryden Press, Holt, Rinehart and Winston, Inc, New York.

Fajariah, S., (2016), Penggunaan Media Video Untuk Meningkatkan Minat Belajar IPA Kelas IV SD Negeri Bakalan, Jurnal Pendidikan Guru Sekolah Dasar,7 (5): 692-702.

Hamalik, O., (2008), Media Pendidikan, Citra Aditya Bakti, Bandung.

Purwono, J., Yutmini, S., dan Anitah, S., (2014), Penggunaan Media Audio-Visual Pada Mata Pelajaran Ilmu Pengetahuan Alam Di Sekolah Menengah Pertama Negeri 1 Pacitan, Jurnal Teknologi Pendidikan Dan Pembelajaran, 2(2): 127-244.

Slameto, (2010), Belajar \& Faktor-Faktor yang Mempengaruhi, Rineka Cipta, Jakarta. 